\title{
Determining research priorities for clinician-initiated trials in infectious diseases
}

David L Paterson MB BS(Hons), PhD, FRACP. Professor of Medicine, ${ }^{1}$ and Infectious Diseases Physician $^{2}$

On behalf of the Steering Group of the Australasia Society for Infectious Diseases Clinical Research Network*

1 Centre for Clinical Research, University of Queensland, Brisbane, QLD.

2 Infectious Diseases Unit, Royal Brisbane and Women's Hospita, Brisbane, QLD.

david.antibiotics@ gmail.com

*The Steering Group of the Australasian Society fo Infectious Diseases Clinical Research Network: Allen Cheng Anton Y Peleg,

Benjamin P Howden,

David R Murdoch,

Emma S McBryde, lan J Woolley, Joshua Davis,

Louise A Cooley,

Monica A Slavin,

James Owen Robinson, Ronan Murray,

Sharon C-A Chen,

Tania C Sorrell, Tony M Walls,

Narin Bak, Anna P Ralph, Sally M Havers, Tiffany M Brown

David L Paterson.

MJA 2013; 198: 270-272 doi: 10.5694/mjal2.11703
R andomised controlled trials (RCTs) are accepted as the best type of study to assess the effects of health care interventions and therefore have a pivotal role in evidence-based medicine. ${ }^{1}$ A new paradigm is emerging whereby RCTs are now being undertaken by a network of clinicians. ${ }^{2}$

Clinician-initiated RCTs have several features that differentiate them from industry-sponsored studies. They are more likely to compare generically available, off-patent medications, or to study processes of care or non-pharmacological interventions. As clinician-initiated trials are financially independent of industry, with their funding source being governmental research organisations (eg, the National Health and Medical Research Council [NHMRC]), the results are viewed by clinicians as more credible. ${ }^{3}$ The NHMRC has already demonstrated a willingness to fund clinician-initiated RCTs, as shown by the success of networks such as the Australian and New Zealand Intensive Care Society Clinical Trials Group. ${ }^{4-7}$ The impact of their successfully completed trials on practice change, cost savings and improved patient outcomes has not been formally measured but is likely to be significant.

Another key advantage is that clinician-initiated RCTs tend to investigate issues that clinicians find most important and relevant to their practice. Moreover, the process of engagement with other clinicians is a crucial one. If investigator-initiated studies are to successfully recruit patients, there needs to be an appreciation by other clinicians that the studies have realistic comparators and clinically significant end points.

To facilitate physician engagement and training in clinical trials methodology, the Australasian Society for Infectious Diseases Clinical Research Network (ASID CRN) was established in 2009. This report summa-

Objectives: To determine research priorities of infectious diseases physicians for clinician-initiated randomised controlled trials (RCTs).

Design, setting and participants: Online survey of infectious diseases physicians in Australia and New Zealand.

Main outcome measures: Research priorities for, and perceived barriers to, clinician-initiated RCTs.

Results: $122 / 550$ infectious diseases physicians (22\%) responded to the survey. The five highest ranked proposals for clinician-initiated RCTs were in the areas of prosthetic joint infections, septic arthritis and osteomyelitis of native joints, Staphylococcus aureus bloodstream infections, diabetic foot infections and the treatment of serious multiresistant, gram-negative bacterial infections. Lack of funding was the most important perceived barrier to participation in clinicianinitiated RCTs.

Conclusions: The research focus of infectious diseases physicians - optimal treatment of commonly encountered serious infections - highlights a lack of well conducted RCTs in this area.

rises the results of an online survey of infectious diseases physicians, conducted by the ASID CRN, to establish its research priorities.

\section{Methods}

In 2012, a self-reported online questionnaire-based survey was administered on behalf of the steering group of the ASID CRN. The survey was developed by the ASID CRN steering group, who compiled a list of more than 100 potential studies: 42 potential randomised controlled trials, 20 epidemiological studies and 40 observational studies/registries. These studies pertained to bacterial infections (69 of the nominated studies), viral infections (18), fungal infections (10), mycobacterial infections (3) and general aspects of clinical infectious diseases practice (3).

A "short list" of these studies was selected by the ASID CRN steering group to be sent to the entire community of members of ASID, comprising most practising infectious diseases physicians in Australia and New Zealand. The ASID members were asked to rate the proposed studies within each group: (a) RCTs, (b) epidemiological studies, and (c) registries of specific infectious diseases, using a numerical scale (with 1 being of little likely clinical significance and 5 being of greatest clinical significance).

To determine the feasibility of the proposed studies, the physicians were also asked to estimate the number of patients seen at their hospital in the past year with each of the conditions relevant to the proposed clinical trial. Additionally, they were asked to describe barriers to enrolment of study patients at their hospital.

\section{Results}

Of the 550 clinicians approached online, $122(22 \%)$ responded to the survey. The RCTs ranked by the ASID members as having most potential clinical significance are listed in Box 1 . Foremost among these were RCTs investigating prosthetic joint infections, native joint septic arthritis or osteomyelitis, Staphylococcus aureus bloodstream infections, foot infection in diabetes and serious infections due to gram-negative bacilli. Clinician estimates of case loads per annum, and hence the number of subjects eligible for recruitment into these studies, ranged from 600 to 700 for the studies on prosthetic joint infection and gram-negative bacilli; 1000 to 2000 for those on native joint infections; and 2700 for foot infections in diabetes. 


\begin{tabular}{|c|c|c|}
\hline & Mean score* & Protocol title \\
\hline 1 & 3.97 & $\begin{array}{l}\text { Early prosthetic joint infections managed with debridement and } \\
\text { retention: } 6 \text { weeks of intravenous antibiotics versus } 2 \text { weeks of } \\
\text { intravenous antibiotics and prolonged oral antibiotics }\end{array}$ \\
\hline 2 & 3.83 & $\begin{array}{l}\text { Native joint septic arthritis or osteomyelitis: } 6 \text { weeks of intravenous } \\
\text { antibiotics versus } 2 \text { weeks of intravenous antibiotics and prolonged oral } \\
\text { antibiotics }\end{array}$ \\
\hline 3 & 3.82 & $\begin{array}{l}\text { Uncomplicated Staphylococcus aureus bloodstream infections: } 2 \text { weeks } \\
\text { of intravenous antibiotics versus } 1 \text { week of intravenous antibiotics and } 1 \\
\text { week of oral antibiotics }\end{array}$ \\
\hline 4 & 3.74 & $\begin{array}{l}\text { All oral antibiotic regimen versus prolonged intravenous antibiotics for } \\
\text { diabetic foot infection }\end{array}$ \\
\hline 5 & 3.43 & $\begin{array}{l}\text { Meropenem versus piperacillin-tazobactam for serious infections caused } \\
\text { by an extended-spectrum } \beta \text {-lactamase producer }\end{array}$ \\
\hline 6 & 3.38 & $\begin{array}{l}\text { Enterococcal endocarditis: ampicillin-gentamicin versus ampicillin/ } \\
\text { ceftriaxone }\end{array}$ \\
\hline 7 & 3.30 & $\begin{array}{l}\text { Fosfomycin versus ertapenem for urinary tract infections caused by an } \\
\text { extended-spectrum } \beta \text {-lactamase producer }\end{array}$ \\
\hline 8 & 3.26 & $\begin{array}{l}\text { Daptomycin versus vancomycin for methicillin-resistant S. aureus } \\
\text { bloodstream infections with a minimum inhibitory concentration of } \\
\text { vancomycin of } 2 \mathrm{mg} / \mathrm{L}\end{array}$ \\
\hline 9 & 3.25 & Short (2-day) versus standard (5-day) intravenous treatment for cellulitis \\
\hline 10 & 3.23 & $\begin{array}{l}\text { 14-day versus } 7 \text {-day antibiotic course for bloodstream infections caused } \\
\text { by gram-negative bacilli }\end{array}$ \\
\hline 11 & 3.11 & $\begin{array}{l}\beta \text {-lactam plus aminoglycoside combination therapy versus } \beta \text {-lactam } \\
\text { monotherapy for serious Pseudomonas aeruginosa infections }\end{array}$ \\
\hline 12 & 3.09 & $\begin{array}{l}\text { Topical versus topical plus systemic decolonisation regimen for patients } \\
\text { with recurrent S. aureus infections }\end{array}$ \\
\hline 13 & 2.75 & $\begin{array}{l}\text { Extended/continuous infusion versus bolus infusion of } \beta \text {-lactam therapy } \\
\text { for infections in patients with neutropenia }\end{array}$ \\
\hline
\end{tabular}

* Surveyed infectious diseases physicians were asked to rank each study proposal on a scale of 1-5 ( $1=$ of little likely clinical significance; $5=$ of greatest clinical significance). The mean score of 122 surveyed clinicians is given.

The surveyed clinicians also supported further study of emerging infections (eg, multi- or extensively drug-resistant tuberculosis or unexplained encephalitis) by way of registries or epidemiological studies.

Barriers to performance of clinicianinitiated studies are listed in Box 2. The most commonly perceived barrier was lack of funding for conducting studies, followed by absence of infrastructure or study personnel, and lack of time owing to clinical commitments.

\section{Discussion}

A number of features dominated the research preferences of Australian and New Zealand infectious diseases physicians. RCTs investigating optimal treatment of commonly encountered infections were highly ranked, highlighting the lack of well conducted RCTs in this area. Investigations into optimal therapy of antibiotic-resistant organisms were also identified as a priority.

Clinician-initiated research presents a number of advantages over RCTs proposed by Australian and New Zealand infectious diseases phy- sicians dealt with reducing the duration of courses of intravenous antibiotics (Box 1). RCTs whereby medications are used less are unlikely to be of interest to industry. RCTs that allow the rigorous evaluation of recommendations in guidelines are likely to be of particular value to clinicians, and those that reduce the duration of intravenous antibiotic courses are likely to reduce costs for governments and, potentially, reduce adverse events for patients.

Steering groups, comprising both researchers and clinicians, have now been established to develop protocols, seek funding for the trials and initiate the studies most highly ranked by clinicians.

Could the methodology and results of our survey of infectious diseases physicians be of use to other clinicians? More than 90 research networks of collaborating clinicians currently exist in Australia (http:// australianclinicaltrials.gov.au/). Some of these networks are well established and have been highly productive, completing a number of high-impact studies. ${ }^{4-9}$ Others are nascent, like our own, and may seek to replicate our methodology.

There are significant challenges in the initiation and conduct of clinicianinitiated studies. Foremost of these is funding, which was regarded in our survey as the single largest barrier to studies being conducted. Other potential difficulties included timeconsuming processes for (and cost of) ethical approval, and lack of support and infrastructure in cash-strapped hospital systems. Innovative solutions to these barriers should be sought other research networks (eg, Australian and New Zealand Intensive Care Society Clinical Trials Group) have received funding from foundations

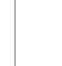


and the NHMRC. In addition, the private hospital system may be an untapped resource for clinician and administrative support.

A limitation of our study was the low response rate of $22 \%$. This is to be expected given the nature of online surveys. The research priorities chosen may not necessarily reflect those of all members of ASID.

We have described here a method for giving practising clinicians a central role in the selection of clinical studies. We hope that this will facilitate not just the planning and conduct of these studies, but also their rapid implementation into clinical practice.

Acknowledgements: The members of the Australasian Society for Infectious Diseases who participated in this survey are gratefully acknowledged.

Competing interests: Tania Sorrell has received untied research funds from Gilead Sciences, Merck, Sharp \&
Dohme and Pfizer Pharmaceuticals and has been a member of their respective antifungal advisory boards. Sharon Chen has served on the antifungal advisory board of Pfizer Australia, Merck, Sharp \& Dohme and Gilead Sciences and has received educational grants from Pfizer Australia, Merck, Sharp \& Dohme and Gilead Sciences. Narin Bak has received financial sponsorship for travelrelated educational meetings from Merck. Sharp \& Dohme, Gilead Sciences and Pfizer and honoraria for educational lectures from Merck, Sharp \& Dohme. He has undertaken clinical trials with antivirals and other antibiotics for many other pharmaceutical companies. David Paterson has served as a consultant or on advisory boards for AstraZeneca, Merck, Sharp \& Dohme, Pfizer,

Cubist, Leo Pharmaceuticals, Novartis, Johnson and Johnson, Bayer, Trius and Achaogen, and has received honoraria for educational lectures from AstraZeneca and research funds from Sanofi Aventis.

Received 21 Nov 2012, accepted 14 Feb 2013.

1 Craig JC, Irwig LM, Stockler MR. Evidence-based medicine: useful tools for decision making. Med Aust 2001; 174: 248-253.

2 Nelson MR. General practice trials: the importance of creating evidence. Med J Aust 2012; 197: 363-364.

3 Kesselheim AS, Robertson CT, Myers JA, et al. A randomized study of how physicians interpret research funding disclosures. N Engl J Med 2012; 367: 1119-1127.

4 Myburgh JA, Finfer S, Bellomo R, et al. Hydroxyethyl starch or saline for fluid resuscitation in intensive care. N Engl J Med 2012; 367: 1901-1911.

5 Dulhunty JM, Roberts JA, Davis JS, et al. Continuous infusion of beta-lactam antibiotics in severe sepsis: a multicenter double-blind. randomized controlled trial. Clin Infect Dis 2013; 56: 236-244.

6 ANZIC Influenza Investigators, Webb SA, Pettilä V. Seppelt I, et al. Critical care services and 2009 HIN1 influenza in Australia and New Zealand. $N$ Engl J Med 2009; 361: 1925-1934.

7 NICE-SUGAR Study Investigators, Finfer S, Liu B, Chittock DR, et al. Hypoglycemia and risk of death in critically ill patients. N Engl J Med 2012; 367: 1108-1118.

8 Zwar NA, Hermiz O, Comino E, et al. Care of patients with a diagnosis of chronic obstructive pulmonary disease: a cluster randomised controlled trial. Med J Aust 2012; 197: 394-398.

9 Harris MF, Fanaian M, Jayasinghe UW, et al. A cluster randomised controlled trial of vascular risk factor management in general practice. Med $\rfloor$ Aust 2012; 197: 387-393. 